\title{
GENDERED CITIZENSHIP: A CASE STUDY OF PAID FILIPINO MALE LIVE-IN CAREGIVERS IN TORONTO
}

\author{
Dionisio Nyaga ${ }^{*}$ \\ Social Justice Education, University of Toronto, \\ 252 Bloor Street West, Toronto, Ontario M5S 1V6, Canada \\ email: dnyaga.nyaga@mail.utoronto.ca \\ Rose Ann Torres ${ }^{* *}$ \\ Sociology and Equity Studies in Education, University of Toronto, \\ 252 Bloor Street West, Toronto, Ontario M5S 1V6, Canada \\ email: rose.torres@utoronto.ca
}

Published online: 15 January 2017

To cite this article: Nyaga, D. and Torres, R. A. 2017. Gendered Citizenship: A case study of paid Filipino male live-in caregivers in Toronto. International Journal of Asia Pacific Studies 13 (1): 51-71, http://dx.doi.org/10.21315/ ijaps2017.13.1.3

To link to this article: http://dx.doi.org/10.21315/ijaps2017.13.1.3

Nation-states tend to be coded as feminine, "the motherlands" that procreate citizens. In Italy, Africa is a single trope of the female body (Carter 1997) where African women migrants have been popularly classified as prostitutes, those who sell themselves and are resold as commodities, and as the most expendable of all human populations, the most easily exploited (Merill 2011: 1559)

\begin{abstract}
Philippines is considered as a major provider of caregiving services in Canada. Caregiving has historically been identified as feminine labour. As such, providing paid caregiving has always been associated with immigrant women. Policies are thus built to control this work and mostly they tie with the masculine culture of the society. In Canada, live-in caregiving is very gendered and masculine, and as such it discriminated men of colour. This paper is focused on a case study that was done in 2014 in Toronto. There were three paid Filipino male live-in caregivers who participated in this study. The study applied qualitative narrative research methodology. The purpose of this article is to discuss and analyse the participants' experiences and understand how Canadian hegemonic and imperial
\end{abstract}


masculinity shapes citizenship and policy in a racialised and gendered manner. Within this argument, we explore in the introduction of this article the discourse of masculinity. We also look at the history of Live-in Caregiver Program in Canada. Additionally, we deliberate and examine the participants' narratives on gendered citizenship, gendered policy, and the nature of their job. The conclusion is based on the narratives of the Filipino male live-in caregivers and their discrimination in caregiving work on the basis of their citizenship and masculinity. The conclusion also looks at how they are able to negotiate their salary, their time to work, and how they work with their clients.

Keywords: Gendered citizenship, gender studies, Filipino caregivers, Filipinos in Canada, live-in caregiving

\section{INTRODUCTION}

Masculinity as a discourse shares responsibilities and defines behaviours of men and women (Brittan 1989; Carrigan, Connell and Lee 1985; Connell 1995, 2000; Williams 1995). To do this, masculinity creates spaces that need to be occupied separately by men and women. As such, women and men are placed in private and public spaces, respectively. Consequently, masculinity identifies the public and private spaces as rational and irrational spaces correspondingly, and as such it is expected that bodies that occupy such spaces to embody those characteristics. Since men are supposed to be rational, competitive, non-emotional and strong they are deemed as public bodies and as such they are expected to be paid, hence making the man the breadwinner of the family (Brittan 1989; Carrigan, Connell and Lee 1985; Connell and Messerschmidt 2000). Correspondingly, men as occupants of public sphere have more economic advantage than those who occupy the private space.

The public space is designed as a space of civility and control, while the private as a space of degeneracy. Consequently, those who occupy such space are deemed as lawless and out of order. Accordingly, when a masculine body which is free and mobile enters the private space it symbolises law and civility. In most instances, the law stumps its authority and power in the private space as a way to bring law and order in the disorderly sphere. The argument is that a man represents the law since he is the one who creates the law and becomes a creation of the same law. In most instances the law will fail to watch on itself. The illegality of power can be seen in terms of its policing effects on some while precluding others. This means that even at home, a woman is still squeezed to the edges of the 
private space. The private space is a border or prison for the woman and it is in this space that real illegality of law is made alive.

On the other hand, a woman is expected to occupy the private space. Intrinsically, women are expected to be docile, irrational, loving, emotional and caring, and as such taking care of the children and the house becomes their responsibility (Brittan 1989; Connell 2000; Williams 1995). But as much as they are expected to be in the private space sometimes the world may invade the home (Bhabha 1994). This means that they are supposed to meet the emotional needs of a competitive and rational public man. This is because the public space has immense physical and mental burnout due to the intense competition among masculine men. As such the woman is supposed to offer comfort to the man after bruising battle in the public space.

Just as masculinity is able to define the character and responsibilities of women and men in our society, it is possible for it to shape and redefine the character and behaviours of nation-states. On a macro level, masculinity discourse is able to subdivide the world into a masculine and feminine nation-state. The world and by extension the nation state is a space that is surveyed into masculine and feminine. According to Arrindell et al., (2003) "Empirical data with country-level indices have shown in relation to gender roles that in feminine countries men are allowed to be gentle, feminine, and weak, whereas in masculine ones women should be gentle and feminine and nobody should be weak" (54). Through this, we deduce that societies carry with them either masculine or feminine character.

It should be recognised that masculinity/gender interlocks with race. The two concepts orient and are oriented by colonialism. As such, when these two concepts are invoked as tools of oppression they employ similar evaluation meant to suppress and subjugate the oppressed communities. Both race and masculinity use rationality, competitiveness, strength and violence as a way to undermine the other. Both of this concepts work towards creating a world of public and private dualism. The two concepts work towards affirming the Whiteman as the standard along which all other masculine and racialised bodies should be measured and accepted. The two colonial concepts work together towards creating a world of civility versus degeneracy or lawlessness. This means that those who occupy spaces of civility are rational and more masculine and as such can be trusted. Those who occupy the lawless spots are identified as not belonging, irrational and as such cannot be trusted. The fact that they cannot be trusted means that law has to be made for them to control their environment and movement. As such, the civil defines the movement of those who occupy spaces of degeneracy such that they cannot access the public space. This ultimately 
can be seen in terms of migration laws as well as labour process where racialised Filipino men are meant to live in spaces of exception. These are spaces of illegality where masculinity through patriarchy interlock with race to deny while at the same time allowing access to power, prestige and privilege for the paid male live-in caregivers.

\section{HISTORY OF LIVE-IN CAREGIVER PROGRAM IN CANADA}

Before capitalism became the world economic order, men and women used to share in caregiving. Extended family would also help in child rearing. This changed and today women continue to be defined as major caregivers (Connell 2000; Gillis 1995; William 2009). This is because, for capitalism to thrive, new changes had to be adopted. Capitalism brought with it the creation of the city through the eviction of some bodies deemed undesirable. Among those evicted from the city were the traditional extended family units. The city became the place for the nuclear family and as such was seen as civilised, and modern. The nuclear family became synonymous with urbanism, modernity and rationality. Those who failed to fit into the nuclear units were cast-off into rural or reserve spaces. In Canada, this led to the formation of First Nation reserves. The reserve was supposed to be a space for aboriginal peoples who were regarded as less human and the degenerates (Wamley 1999).

While this was happening, the city was also being redefined into the public and private sphere. The private sphere was a place to provide emotional and reproductive work. It was supposed to be for reproduction and not for economic purposes. This space was defined as emotional, irrational and non-competitive (Connell 2000; Brittan 1989). Women who were in the city were supposed to undertake such emotional work. The house was defined as a private space where women were supposed to bear and take care of children and undertake other household chore. In contrast, the public space was supposed to be rational, competitive, non-emotional and masculine (Wamley 1999). This schism allowed unequal power relations between men and women (Brittan 1989; Connell 2000; Williams 1995). Men were supposed to be the only people occupying such spaces. The public space was paid through salaries and wages. Since men were the only family income earners, they had an upper hand on how the home was supposed to be run. This gender binary allowed men to own and control the public sphere and maintain its masculine image while simultaneously denying identifying others (women, racialised, disabled) as space raiders. 
Rules, policies and laws were set to keep any undesirable body from entering the public space.

Soon a feminist wave swept through Canada seeking the emancipation of women. This movement was mostly led by middle class white women who were pursuing to be recognised in the public space; for instance being employed and being able to go to public schools. After the 1960s second wave of feminism, white women were granted freedom to join educational institutions like universities. This made it possible for them to be tolerated in the public space through employment, since they had entered the rational realm through education. This seemed to be a breakthrough for the white women. But for various reasons a white woman still had to look for somebody to leave her children to (Williams 1995). Consequently, women of colour had to be employed to take care of the children left behind by the empowered white Anglophone middle class women. These women of colour were supposed to be paid to provide emotional work to white families (Khan 2009). The economic caregiver became the sacrifice meant to empower the white woman. The private sphere which used to be unpaid became an economic space. This was another moment where the world entered the space. In such an encounter, the private space has to be reorganised and controlled. When a woman of colour enters a space which used to be a white woman's space then extra vigilance is needed. In Canada, this led to creation of the Domestic Worker policy that would organise caregiving in private spaces.

Caregiving in Canada started with the employment of Anglophone women. Women from Britain were brought to Canada to take up private duties like taking care of children and the elderly. They would also be allowed to marry Canadian bachelors who would allow them to enter the Canadian space as citizens (Khan 2009). This allowed British caregivers to enjoy better citizenship because of their language and colour. Later, women from Eastern Europe took over caregiving work from Western women, and since they could not speak English, they were treated less favourably than their Anglophone predecessors. Not long after, women from the Caribbean took over caregiving work from European women (Khan 2009). To be allowed to work as a caregiver, black women had to undergo rigorous medical examination to identify whether they had communicable and sexual diseases (Khan 2009; Lindio-McGovern 2003). This was because of the fear of the black body as impure and as such could contaminate the masculine white Canadians. They were also required to inform the consular in their country whether they had a child. This was out of the fear that the Canadian nation did not want its whiteness to be diluted. Though the white Canadian society was afraid of the black skin, it also needed its labour in order to 
sustain itself as modern. A black body is associated with degeneracy, diseases and irrationality (Fanon 1967). For a black woman it becomes a double-edge problem. Her space is gendered and racialised hence the white system applies multiple system of policing the body. In terms of immigration policies, a racialised body is under constant and continuous watch. The aim is to seclude it in spaces of degeneracy so that it does not dirty the pure white state. But in case of the need for black women as in the case of caregiving, they are subject to immense checks. It is a kind of hysteria that wants to keep out a body while simultaneously looking for it for your own survival (Mbembe 2004). The black woman's body lives in liminality. When needed, it is sought after but when not in need, it is discarded.

In Canada, the women were expected to stay with the employer. They were not supposed to be seen in public spaces. It was a way of controlling the black body from entering the white public space. The white live-in caregivers had privileges of citizenship, but the black women were denied. They would be paid low wages that were not commensurate with their work. The instructions were very clear that upon finishing their contract they had to go back to their countries (Khan 2009). After the exit of black women, the Filipino women came. Currently, the Philippines is a major exporter of caregiving services in Canada (Khan 2009; Lindio-McGovern 2003, 2004).

In the early days, Filipino women were supposed to return to their country upon the expiration of their caregiving contract. Soon however, a big outcry erupted, led by Filipino rights organisations calling for the reinstatement of permanent residency for the live-in caregivers. This led to the review of the Domestic Caregivers to Live-in Caregiver Program. In Canada, provision of paid caregiving services is regulated by the Live-in Caregiver Program (Khan 2009). This program allows Filipino women caregivers to work with one employer for two years, upon which they can apply for permanent residency. Though this was seen as a victory (in that at the end of two years they will get their permanent residency), it has become a tool used by the employer to control, oppress and manipulate the caregivers (Lindio-McGovern 2004). The permanent residency was used as a carrot-and-stick to control and oppress the Filipino live-in caregivers. White families oppress and abuse these women. Merill (2011) says that:

In her study of immigrant domestic labor in Italy Jacqueline Andall points out that racialized differentiation and the absence of legal protection amplify forms of exploitation such as poor working conditions, including an inability to perform motherhood, low wages, excessively long hours, an absence of free time, and forms of 
sexual harassment. Indeed, employers use racial hierarchies to determine levels of pay, working conditions, and treatment. (Andall cited in Merill 2011)

The caregiver has to toil in the abuse so that she can get Canadian residency. This program stipulates that women who undertake this kind of work should stay with the employer. This allows the women to be constantly surveyed by their employer. As much as the policy is supposed to regulate the private work place, it ends up policing the employee and simultaneously fails to monitor the employer.

A case in point is that the program highlights more reasons why a caregiver can be deported. Among them is failure to comply with the instructions of the employer. If the employer does not like the caregiver's work, they can decide to terminate the caregiver's work which will render the caregiver deportable. While this is being done, the policy fails to identify what can be done in case the employer is oppressive to the caregiver. This policy lacuna gives the employer more leeway to undermine and oppress the Filipino caregivers. Among the issues that the live-in caregivers face are sexual, physical and emotional attacks by their employers. These scenarios go unreported since the caregiver is afraid that the employer will dismiss her, rendering her deportable.

A case in point is the gendered Live-in Caregiver Program policy (Khan 2009; Lindio-McGovern 2003). The policy identifies only women as caregivers. This means that when Filipino men want to work as caregivers, they are denied opportunities. On the other hand, the policy focuses more on disciplining and punishing those who occupy private space as caregiver. Laws and regulations are applied to surveil spaces of exception since this are defined as uncivilised. As such when a migrant Filipino woman occupies such spaces, the surveilling lens of Live-in Caregiver Program focuses on her constantly and continuously. This policing switches off when a Filipino man enters the private space. Williams (1992) says that men receive more dividends from masculinity than their women counterparts. This means that the man who chooses to work as a caregiver and gets caregiving work can work with minimal surveillance (Robinson 1979). But due to cultural sexualisation of caregiving it is hard for an immigrant man to get employed by any employer. But if a man gets the job, it is easy for them to avoid the surveilling eye of the Live-in Caregiver Program policy. One of the participants had this to say:

It is very hard for men to get this kind of work. You know how curious our society is when a man starts doing caregiving work. 
You know from the Filipino culture, men are not supposed to do this kind of work. When we come here, we take this kind of work because we want to survive. But to get one is a problem. Some employers already become suspicious when you ask for this kind of work. They question your intent.

The Philippines has been undergoing intense economic upheaval since the 1990s (Lindio-McGovern 2003, 2004). The World Bank and International Monetary Fund (IMF) economic policies such as the structural adjustment programs have had an adverse effect on Filipino communities (LindioMcGovern 2003). Among them is the high unemployment rate. This has forced many Filipinos to seek greener pastures in the West. The Philippines is known to provide caregiving services to Canada (Lindio-McGovern 2003, 2004; Nyaga 2015) which is mostly done by migrant Filipino women (Galabuzi 2006). Recently, Filipino men have started taking up caregiving work in private homes in Toronto (Nyaga 2015). Filipino men and women have to undertake this kind of work since the Canadian masculine defines the Philippines and its citizens as docile, emotional, submissive and nice (Khan 2009, Lindio-McGovern 2004). Galabuzi (2006) states that since Canadians do not want to undertake these kinds of jobs, migrant Filipino women are expected to fill in that labour vacuum. Labour precariousness, coupled with the belief that a Filipino woman is docile and submissive (Torres, 2012) makes it easy for Filipino women to be employed and controlled by the employer. It also makes it easy to pay them less.

Through the Live-in Caregiver Program, Canada is able to define and influence the roles and responsibilities of other nation-states. According to Khan (2009), Canadian Live-in Caregiver Program has been identified as the best program in the world by the International Labour Organisation. This makes the program credible globally, hence reimaging Canada as rational and civil space. Just like law is made to police the spaces of exception, so does the live-in caregiver policy. By gaining credibility, the policy subsequently gains the power to walk over those who occupy private space. The illegality of this policy can only be felt by a female live-in caregiver while at the same time its policing stops when a white woman or a Filipino man enters the space. Worldly credibility of the Live-in Caregiver Program gives a go-ahead for incising terror on the bodies of women immigrants. This credibility provides the licence for its application in other countries like Philippines. The policy is generalisable and acceptable to others countries since it is seen as rational. Such determination of a policy is also seen as scientific and the truth seems depicting the process of knowledge representing power (Foucault 1980). The Philippines has a lot of 
colleges that are supposed to offer caregiving degrees and diplomas that fit the quality required by the Live-in Caregiver Program. The program expects qualified caregivers to work in Toronto private homes. This shows how Canada's masculine caregiving policy is able to be enacted internationally.

\section{Gendered Citizenship}

Philippines has been providing caregiving services to the world through its citizens. In addition, Philippines is unable to offer employment to citizens and this why Filipinos migrate to other countries. One of the participants had this to say:

Most of us opt to take up this work because back home it is not easy to get a well-paying job. I therefore was not able to meet the needs of my family. This is the reason I had to leave the Philippines so that I can earn Canadian dollar which as you know is a lot of money when you compare it with pesos. I am now able to take care of my family back home.

According to the masculinity discourse, a man is supposed to offer security to his family. This means that the man has to be a breadwinner.

This feminisation of a nation-state becomes a key identifier of its citizens when they are in foreign lands. It determines what kind of work such migrants can do when they cross the border (Aguilar 1989). This is the reason why Canadian hegemonic white masculine discourse through the Live-in Caregiver Program continues to identify Filipino women as caregivers.

Canada is also able to push its economic agenda through international bodies like the World Bank and IMF. This is what happened to the Philippines when Bretton Wood Institutions came calling on the nation. In 1990s Bretton Wood Institutions like the World Bank and IMF proposed Structural Adjustment Programs in the Philippines (Lindio-McGovern 2003, 2004). These policies forced the government to rationalise (masculinise) its operations in public service provision. This policy was supposed to reduce the government with the aim of cutting down costs. This led to the retrenchment of public programs and subsequent early retirement of public officers. Former civil servants left for Western countries in search of greener pastures. For those who could not afford to leave the country, they opted to undertake nursing and other caregiving courses in college to prepare to move to other countries as care providers (Lindio-McGovern 2003, 2004). 
The Philippines continue to provide caregiving services to Canada (Khan 2009; Lindio-McGovern 2003, 2004; Nyaga 2015). The country has introduced many caregiving courses to train young people in undertaking caregiving work in the West. Many of the trainees used to be women. This is because in the Philippines, women are regarded as good caregivers. Consequently, women were enrolled in such colleges in large numbers. Through exportation of caregivers to Canada, the Philippines could meet its balance of trade (Lindio-McGovern 2003). Currently, Filipino men are entering the paid private caregiving professions. According to Nyaga (2015), men of Filipino descent have been undertaking live-in caregiving work in Toronto. This is because most migrant Filipino men who are educated cannot find a masculine white collar job in Toronto. According to one of the participants:

I have a degree and I was a licensed medical practitioner in the Philippines. In fact, I used to work in the hospital. My family also set up our own clinic. When I came here, I tried to apply for a job based on my line of work. But employers told me that I am not qualified because I do not have Canadian education and licence. Additionally, I was told that my work experience from the Philippines is not acceptable here. I still need to have a Canadian work experience.

The public space in Canada is oriented towards white hegemonic masculinity. This means that everyone who comes in is treated with suspicion and seen as space an invader (Puwar 2004). There is a gaze the migrant body receives from the spaces and bodies within that identifies it as an outsider. This can happen through the constant, continuous and unverifiable watch that an outsider of the somatic normal receives from white men and the space they occupy. To keep migrant Filipino men out, white masculine spaces uses education (rationality) and experience as an alibi to deny those jobs. According to one of the participants:

Every time I go to my employer, his/her relatives always ask me if I know what I'm doing. I have a degree in physiotherapy. I went for a series of interviews, and still my employer and his/her relatives do not trust me. Is it because I am a man I do not know how to take care of people? I took care of my children when they were young. I also took care of my grandparents when I was in the Philippines. It makes me upset why I am being questioned all the time when it comes to caregiving. 
For one to be allowed to occupy such spaces, they should downgrade their masculinity in relation to white hegemonic masculinity. Racialised Filipino migrant women can easily be accommodated into the white space since they are the ones who undertake paid reproductive chores in the private space. One of the participants stated that:

Do I need to be a woman to be a caregiver? I know how to take care of human being. I was trained by my family. I was trained in school, that is why I am in Canada. I am a caregiver because I love to take care of people who are in need of help or assistance. But I guess, it is difficult in our society to see a man being a caregiver, which I understand. I am hoping that one day men will be accepted fully as caregivers.

This is necessitated by the Canadian white masculine mythology that Filipino women are loving, submissive and uncritical (Galabuzi 2006). These characteristics make it easy for them to be taken up in white masculine spaces (Lindio-McGovern 2004). Galabuzi (2006) has talked about essences where racialised Filipino women are placed in precarious ghettoised jobs, making it possible for the employer to exploit them. This is so because they have no valid Canadian citizenship and as such, they are seen as bodies that do not have rights.

To be employed, many racialised men opt to subjugate their masculinity and undertake private chores in the private spaces. According to Nyaga (2015), paid live-in caregivers undertake emotional work in private spaces as a ploy of future accommodation into the white hegemonic masculine spaces. Most of them claim that they accept caregiving because it is a stepping stone to the realisation of them entering white hegemonic job spaces. These men are able to go back to school before or after their caregiving term comes to an end. This is done with the knowledge of their employers. This is not the case with Filipino women, who have to seek permission even for very simple personal needs. One participant in this study said:

When I came here, it was very hard to get a job. I therefore decide to try caregiving since I had to survive. Back in the Philippines I had a good job but it was not paying well. I thought that when I come here I will get a good job that is close to what I was doing in the Philippines. By adopting to be a caregiver, I wanted to get some way of survival as I prepare myself to get back to college to upgrade my profession so that I can get a good job in the office. I am in the 
process of enrolling for college and I have the support of my employer.

But as much as this is the case, many Filipino male caregivers are still constrained and interned in those spaces after finishing their contract. This is because they do not have enough Canadian job experience to enable them to work in the public space. Their skin colour also denies them entry into Canadian public spaces. To that end, as much as some migrant masculine bodies may subjugate their masculinity as a ploy to enter the hegemonic white masculine space, they still face constant eviction from those spaces. Using panoptic technics of language, bodily gestures and behaviours deemed as white and manly, the Filipino men are identified as not fit to enter the white masculine labour space. The fact that the migrant Filipino men cannot speak in Canadian accent makes it worse for them. This, coupled with labour laws and policies, allows an uninterrupted sidelining of a Filipino man from accessing gainful employment in Toronto.

This renders Filipino men constrained to perform their masculine responsibilities as the family breadwinner. Instead, their wives take up the role of family provider. This can create a lot of family animosities that lead to multiple social issues for the families. Few, if any, have a moment of opting to go back to their countries. Even though such thoughts may cross their mind, they try to suppress them. Back in the Philippines, people understand that when a person leaves for the West, it means that they are heading for better lives. While in Canada, it is expected that they will be able to play the role of the provider and protector of not only their nuclear family but also their extended families. This is a big identifier of their masculinity. In Filipino cultures, such men are referred to as haligi, which means family cornerstone (Alipio 2013; Nyaga 2015).

The fact that they can permeate national borders tells a lot about their masculinity. That they are free floating and mobile. To that extent, such a person is treated like a king. It is a sign of a person who is able to overcome adversities in his own country and build a future in another country. LindioMcGovern (2004) asserted that the Philippines created a policy that would force migrant women caregivers to send some money back to the Philippines, failing which would result in them facing repatriation. Going back to Philippines would pose them as failures. One of the participants said:

I would rather take up caregiving here than going back. Back in the Philippines, it is very hard to survive. The pay you receive is not enough to take care of yourself and your family. Being in Canada as 
a caregiver affords me to take care of my family and I am also left with enough to take care of myself. This country provides a lot of opportunities for us if we work hard.

\section{Gendered Policy}

Live-in caregiving work in Canada is regulated by the Live-in Caregiver Program. The policy defines the roles and responsibility of a caregiver. It looks at caregiving as women's work (Brickner and Straehle 2010; Kalaw and Gross 2010; Khan 2009; Nyaga 2015; Stiell and England 2011). Caregivers are supposed to live with the employer for two years, after which they can apply for permanent residence. The promise of citizenship brought by permanent residency allows frequent exploitation and abuse of female caregivers by their employer (Walia 2011). This is because in the event that the employer renders a caregiver unemployed, they can be deported by the state. Due to this fear of deportation, many live-in caregivers have to toil despite the exploitation and abuse they receive from their employer.

The live-in caregivers are made to live in spaces of exception by the laws and policies that regulate caregiving in Canada. Live-in Caregiver Program creates policed bodies in the form of live-in caregivers by placing them under the watch of their employer. The policy enters the home to police the live-in caregiver while simultaneously shying away from the employer. The caregiving space becomes a frontier where the police are supposed to bring law and order. State law become a space where laws and policy sanctions state violence on the body of live-in caregiver. This is done through suspension of the law as it enters the white private home. The home is a frontier for two reasons. It is a private space where all women who have partial or no citizenship rights at all are expected to live. It is also a frontier because it is occupied by a racialised woman who has no Canadian citizenship rights.

Masculinity defines the private space as emotional and irrational. It is seen as a space of barbarism and as such uncivilised and law has to be brought to its door. This is made worse if a racialised Filipino woman is present. Through this, the Filipino woman is doubly policed based on her gender and race. The policy is supposed to regulate the caregiver and identify its body as a frontier that needs to be controlled. While doing this, the power that the law exudes becomes illegal. The law is supposed to bring peace but for this case it becomes a mechanism to punish and discipline the body. The effect of its illegality is felt in the bodies of Filipino women caregivers, as it stamps its mark on them. It is this process that makes live-in caregivers seen as refugees in camps. The employer's house becomes a 
space of illegality with the support of the law and policies. The policy becomes a wall that is meant to hide the illegality happening in the employer's house while at the same time keeping the live-in caregiver from entering the public space and eventually making it impure.

Filipino women live-in caregivers have been sexually, physically and emotionally abused by their employers (Brickner and Straehle 2010; Kalaw and Gross 2010; Khan 2009; Lindio-McGovern 2003; Stiell and England 2011; Walia 2011). They are overworked and made to do other kinds of work not stipulated in the contract. This is possible because the policy focuses on the live-in caregiver more that it does on the employer. It identifies the consequences that a caregiver can face in case she defies the employer.

Brickner and Straehle (2011) state that the Live-in Caregiver Program is gendered because it identifies women as the only caregivers. What happens when a man takes up paid live-in caregiving work in private spaces? Two things happen. One is that the policy denies the man the opportunity to undertake the work since it believes that he is supposed to be a public figure. This makes it possible for them to be evicted from participating in paid private emotional work. Private emotional work entails a lot of touching (Evans 2011). Masculine culture sexualises any male touching, thus keeping Filipino men at bay from undertaking any private work. By evicting the migrant Filipino male, Filipino masculine culture is used to show the man that they are supposed to be in public sphere. One of the participants said:

The reason for that is due to our thinking on sexual immorality and gender difference when men take up caregiving work. This is not accepted in our culture. Men taking care of older women is not seen as normal. This is because our culture teaches us to respect ladies. We have that... you know. Probably you are aware of some sexual accusations against men.

This shows how colonial transnational migrant masculine culture in Canada is used to deny Filipino men from undertaking caregiving work, by identifying them as belonging in the public sphere.

The Filipino males cannot access the Canadian public space since it is controlled by white men. As pointed out in the beginning, the Canadian space is awash with white masculine national mythology that is meant to keep all migrant men from entering it. One of the participants noted: 
I wonder why it is so difficult to get an engineering job in Canada. I have a degree in engineering from the Philippines. In fact, I have my licence too. Before I came to Canada, I used to work as an engineer in the Philippines for a couple of years. But, when I came to Canada, even a construction job was very difficult to get. Employers wanted me to have a Canadian construction experience. I remember, when I went to a construction site to inquire about job, the workers were looking at me in a very suspicious way.

The gaze and the policy within the public and private space situate a Filipino male in the liminal spaces. Living in the liminal space means being out of place. It is being homeless since one is not accepted in both of the spaces. This space of exception receives intense policing from the state. This is because whatever occupies such a space is deemed degenerative and uncivilised. It is a space of homeless bodies that seems to elicit anxiety regarding state security. It is living in what Bhabha (1994) calls the third space. According to Bhabha, such a space can be transformational and revolutionary. This space allows disturbance and deconstruction of held-forgranted cultural beliefs. It is a space that allows the creation of new possibilities. Bhabha notes that being in this space allows for the identification of other ways of survival.

Since the Canadian masculine national mythology through the Livein Caregiver Program has defined caregiving as emotional, irrational and meant for migrant Filipino women, it is easier for a migrant Filipino man to be accommodated in the private sphere than he is in public space. In fact, the private space becomes a home for the Filipino man. This is because the space where Filipino caregivers are employed is synonymised with the Philippines. The private space is therefore easier for the Filipino man to enter than the public space. One of the participant states:

There are so many jobs in Toronto. But it is difficult to get it. I obtained a degree in the Philippines, but I still cannot get a job. Employers always ask me if I have a Canadian experience. What is this Canadian experience? I am a matured educated man. I can read and write. Therefore I can follow instructions. This is the reason I have to take up caregiving as a way to survive.

To that end, caregiving becomes the only option for the Filipino migrant men to take on in order to survive. To undertake and to fit into this emotional work, Filipino men have to subjugate their migrant masculinity. 


\section{Nature of their Job}

Live-in caregiving work has been identified as Filipino women's job. The Canadian Live-in Caregiver Program defines who does emotional work. The policy identifies paid caregiving as migrant women's work. Consequently, the policy is built under a masculine framework. This means that the policy is gendered and meant to draw guidelines on who is supposed to work as a caregiver and who is not. According to the paid Filipino male caregivers who were interviewed, there are several mechanisms that can potentially expel them from caregiving work. According to one of the participants:

When somebody finds out about my work as a caregiver he/she would be a little bit surprised. Filipinos always say this, "Ano naman ang klase ng trabaho muna yan, pang babae yan," which means, "What kind of work is that, that is a woman's work." I think I understand their concerns, since caregiving involves the caregiver physically holding the clients, for example, in assisting him/her to walk. For some you need to help them change their clothes. But for me, I respect my clients and I always make sure that their dignity is being safeguarded all the time.

Caregiving work is emotional and involves a lot of touching. As such if they undertake this kind of touching they may be construed as sexually abusing the care receivers (Evans 2011). Cultures in the Philippine are defined by colonial masculinity where men are supposed to be breadwinners. Canadian white culture also defines caregiving work as feminine. This makes it impossible for Filipino men to be hired as live-in caregivers, since their gender defines them as public bodies which do not belong in private spheres. They are also seen as outsiders within the Toronto public space. Their skin colour and hair texture make it impossible to enter Canadian white public work spaces. As indicated earlier, Filipino men are left to occupy a third space where they have to look for other means of survival. Consequently, the space allows them to overcome their colonial masculinity by subjugating it so that they can enter into caregiving work. So when there is no option left for them, the closest space is caregiving work. As mentioned by one of the participants:

I could not find a job with my qualification from the Philippines. I have to apply for a job as a caregiver. I need to help my family. I cannot just sit down and wait for a job that is not coming. So I asked my sister who is a caregiver to help me find a job in caregiving. I was able to get a job through my sister who referred me to one of the 
employers she knew. It was an easy job for me, because I used to take care of my grandparents in the Philippines. Also as Filipinos, we take care of our relatives when they are sick or old. We do not usually ask other people to take care of them. They are our family, therefore we have the responsibility to take care for them.

They feel like they are back in the Philippines while in Canada. This makes it possible for them to occupy two geographical spaces simultaneously. This occupation can help the migrant caregivers to survive in a new country.

Bodies and space orient each other. When a Filipino male caregiver gets a caregiving job in Toronto, it becomes more of a reconnection with the self. Due to the fact that we are the spaces that we occupy, we always connect more with their characteristics. This means that we seek to identify with other spaces that look familiar. Colonial masculinity plays its part within the care-giving space based on differentiated treatment between male and female Filipino caregivers by the white woman employer. This is due to the gendered aspect of the Live-in Caregiver Program. The male caregivers have more free time to do what they want. They can afford to move out and visit their friends. They can ask their employers for an increase in their salary. Peter, one of the participants, said:

When I initially worked for her, she did not pay overtime. I asked her whether she knew that our contract was 40 hours and that she had not paid my overtime. I think she gave me 80 dollars for the overtime. I did let her know of my unhappiness. Nowadays, she pays overtime.

What Peter is saying is that he is able to negotiate his salary with his white woman employer. This is because he occupies a masculine space in the private sphere. Due to his masculinity, he is more comfortable and assertive in asking for what he sees as rightfully his. When a public space in the name of a migrant man enters a private sphere, it is able to re-orient such a space to accommodate it. It becomes private and mobile. This comfort could be brought by the synonymity of the private working space with the Philippines. Consequently, the Filipino migrant man can easily identify with himself since the space replicates him. Peter also said:

After 9 o'clock in the morning, I cook and do some housekeeping. It is not heavy work. She keeps ordering me what to do. Sometimes, when she cannot find anything else for me to do, she creates some mess so that I can look like I am doing something. 
Peter is implying is that he is better in doing house work than his employer. When men occupy the private space, they seek to become better than women. This creates animosity between the male caregiver and the employer. Each one of them is trying to assert themselves within the private space. To claim her space, the white woman has to keep instructing the migrant Filipino man what he should do. This is because masculine discourse defines the man as non-emotional. Therefore, when a man shows better caregiving capability than women, they are treated suspiciously (Evans 2011).

Secondly, in private spaces, there is an encounter between whiteness and migrant masculinity. The migrant man keeps asserting his power in his familiar space. The employer who happens to be a white woman is also trying to assert her whiteness in the private space. The private space that was once uncompetitive turns into a war front. It is a violent encounter between race and gender seeking control of the private space, as the Filipino migrant man and the white woman are both in and out of the public space based on their gender and race. Through whiteness, the female employer is supposed to occupy the public space, but due to her feminine body, it is evicted. Alternatively, gender allows the Filipino male to enter the public space but race is used to deny him entry. For him, the private space becomes his only viable alternative. The meeting of race and gender creates a competitive mode over who controls the private sphere. Due to this reason, Filipino males are able to push for agendas that will work for them in asserting their masculinity in private spaces. This gives them more advantage than their fellow women counterparts, since because their masculinity affords them a sense of citizenship while they are in the private space.

As such, most Filipino males undertake more masculine tasks such as driving the employer to work and lifting the care receiver. Intimate work is left for the women live-in caregivers. Filipino men can negotiate the number of hours with the employer. In contrast, the Filipino women do not normally discuss their hours and compensation with their employer in fear of deportation. They are supposed to stay within the house of the employer with minimal movement. It is easy for paid Filipino male live-in caregivers to share responsibilities with their white woman employers. These men are always acknowledged as doing their work better than their counterparts. This shows how masculinity gives citizenship rights to migrant men when they enter private spaces. One of the interviewees said:

We are expected to respects ladies. You have already heard sexual accusations against men who provide caregiving. For some reason I 
think men should take care of their fellow men. In some cases, I also think that we should involve both men and women working together to provide care more especially when the work needs heavy lifting. When it comes to touching, women should be the ones doing it. I should only help in other kind of works like instrumental activities of daily living (ADLs), driving, and running errands in the house.

\section{CONCLUSION}

Hegemonic masculinity continues to define citizenship, policy and nature of work in the caregiving industry in Canada. Based on the narratives of the Filipino male caregivers who participated in this study, they appear to have been discriminated on the basis of their citizenship, gender and policy. While this is so, we cannot avoid identifying instances of revolutions and resistance from the marginalised groups. They may look trivial but they have the power to bring social change. Men are able to subdue normalised masculine cultures and identify spaces where they feel a sense of belonging. For instance, the participants in this study have been able to negotiate their salary, how they work with their clients, and their time to work. Canada plays a fundamental role in shaping the gender of other countries. Under the conservative government, Canadians experienced a heightened masculine role on war on terror. Canada's presence in the war front was visible. Now that a new liberal government seeks to apply diplomacy and engage with less combats, it will be interesting to see how Canadian masculinity develops in international politics. The new Prime Minister happens to employ Filipino live-in caregivers in taking care of his children. It will be interesting to know his stand on the gendered Live-in Caregiver Program.

\section{NOTES}

* Dionisio Nyaga is a PhD candidate at Social Justice Education, Ontario Institute for Studies in Education (OISE), University of Toronto. He has a masters and a bachelor degree in social work from School of Social Work, Ryerson University and is now a lecturer at Ryerson University. Dionisio had published a lot on issues of indigenous knowledge and power as well as on critical masculinity. His practice, research and teaching interests are in the area of critical masculinity, Marxism, curriculum development, post-colonial studies, anti-colonial studies, diasporic and transnational conversations, indigenous practices, and knowledge production and anti-oppressive theories. 
** Rose Ann Torres has a PhD in Sociology of Education and Women and Gender Studies at Ontario Institute for Studies in Education (OISE), University of Toronto, Canada. She has been teaching at Sociology Department at Ryerson University and Trent University, and in the department of Women and Gender Studies at Brock University, Toronto. Her research and teaching interests are in the areas of community engaged research theory and methodology, Indigenous studies, inequities, critical anti-racism, gender variance, politics of resistance, inclusive education, post-colonial theory, anti-colonial theory, feminist theory, transnational studies, and sociology of knowledge. She is currently conducting a community engaged research on "The Diasporic Resiliency, Agency and Resistance of Filipino Women: Roles, Influences, and Experiences."

\section{REFERENCES}

Aguilar, D. D. 1989. The social construction of the Filipino woman. International Journal of Intercultural Relations 13 (4): 527-551.

Arrindell, W. A. et al. 2003. Masculinity-femininity as a national characteristic and its relationship with national agoraphobic fear levels: Fodor's sex role hypothesis revitalized. Behaviour Research and Therapy 41: 795-807.

Alipio, C. 2013. Young men in the Philippines: Mapping the costs and debts of work, marriage, and family life. The Annals of the American Academy of Political and Social Science 646 (1): 214-232.

Bhabha, H. K. 1994. Location of culture. New York. Routledge.

Brickner, R. K. and Straehle, C. 2010. The missing link: Gender, immigration policy and the Live-in Caregiver Program in Canada. Policy and Society 29 (4): 309-320.

Brittan, A. 1989. Masculinity and power. Oxford: Blackwell

Carrigan, T., Connell, R. W. and Lee, J. 1985. Toward a new sociology of masculinity. Theory and Society 14 (5): 551-604.

Carter, D. 1997. States of grace: Senegalese immigrants in northern Italy. Minneapolis: University of Minnesota Press.

Connell, R. W. 1995. Masculinities. Berkeley, CA: University of California Press. . 2000. The men and the boys. Berkeley, CA: University of California Press.

Connell, R. W. and Messerschmidt, J. W. 2005. Hegemonic masculinity: Rethinking the concept. Gender and Society 19 (6): 829-859.

Evans. J. A. 2011. Cautious caregivers: Gender stereotypes and the sexualisation of men nurses touch. Journal of Advanced Nursing 40 (4): 441-448.

Fanon, F. 1967. Black skin white masks. New York: Grove Press.

Foucault, M. 1980. Power/knowledge: Selected interviews and other writings, 1972-1977. New York: Pantheon.

Galabuzi, G.-E. 2006. Canada's economic apartheid: The social exclusion of racialised groups in the new century. Toronto: Canadian Scholars Press.

Gillis, J. R. 1995. Bringing up father: British paternal identities, 1700 to present. Masculinities 3 (3): 1-27. 
Kalaw, T. and Gross, D. M. 2010. Employment standards violations and live-in caregivers' characteristics in British Columbia. Working paper, Metropolis British Columbia, September.

Khan, S. A. 2009. From labour of love to decent work: Protecting the human rights of migrant caregivers in canada. Canadian Journal of Law and Society 24 (1): 2345.

Lindio-McGovern, L. 2003. Labour export in the context of globalization: The experience of Filipino domestic workers in Rome. International Sociology 18 (3): 513-534.

. 2004. Alienation and labor export in the context of globalization. Filipino migrant domestic workers in Taiwan and Hong Kong. Critical Asian Studies 36 (2): 217-238.

Mbembe, A. 2004. Aesthetics of superfluity. Public Culture 16 (3): 373-406.

Merill, H. 2011. Migration and surplus populations: Race and deindustrialization in Northern. Editorial board of Antipode, Italy 43 (5): 1542-1572.

Nyaga, D. 2015. Disturbing masculinity. Saarbrücken: Lambert publishers.

Puwar, N. 2004. Space invaders: Race, gender and bodies out of place. Oxford: Berg.

Stiell, B. and England, K. 2011. Domestic distinction: Constructing difference among paid domestic workers in Toronto. Gender, Place and Culture 4 (3): 339-359.

Robinson, B. E. 1979. A two-year follow-up study of male and female caregivers. Child Care Quarterly 8 (4): 279-294.

Torres, R. A. 2012. Aeta indigenous women healers in the Philippines: Lesson and implication. PhD diss., Institute for Studies in Education, University of Toronto, Canada.

Walia, H. 2011. Transient servitude: Migrant labour in Canada and the apartheid of citizenship. Race and Class 52 (1): 71-84.

Wamley, B. H. 1999. The public importance of men and the importance of public men: Sports and masculinities in nineteenth-century Canada. In Sports and gender in Canada, ed. White, P. and Young, K., 24-39. Toronto: Oxford University Press.

Williams, C. L. 1992. The glass escalator: Hidden advantages for men in the female professions. Social Problems 39 (3): 253-67. . 1995. Still a man's world. Berkeley: University of California Press. 